\title{
Metodología Aprendizaje-Servicio adaptada al confinamiento por COVID- \\ 19: Utilización en la prevención de adicciones
}

Chiara Machía, Rocio Martí ${ }^{b}$, Laura Andrés ${ }^{c}$, Marisa Guillén ${ }^{d}$, Carmel Ferragud ${ }^{\mathrm{e}}$, TeresaGarrigues ${ }^{\mathrm{f}}$, Marisa Ferrándiz ${ }^{\mathrm{g}}$ Jesús Blesa ${ }^{\mathrm{h}}$

aEstudiante del grado en Farmacia. Universitat de València. (chiara.ms@hotmail.com), bEstudiante del grado en Farmacia.Universitat de València. (rociomarti17@gmail.com), ${ }^{\mathrm{c}}$ Estudiante del grado en Farmacia. Universitat de València. (laura.alaquas@hotmail.com), ${ }^{\mathrm{d} D p t o . ~ M e d i c i n a ~ P r e v e n t i v a ~ y ~ S a l u d ~ P u ́ b l i c a, ~ C i e n c i a s ~ d e ~ l a ~ A l i m e n t a c i o ́ n ~, ~}$ Toxicología y Medicina Legal. Universitat de València (marisa.guillen@uv.es), e Dpto. Historia de la Ciencia y Documentación.Universitat de València (carmel.ferragud@uv.es), fDpto. Parasitología y Tecnología Farmacéutica. Universitat de València (teresa.garrigues@uv.es), ${ }^{\mathrm{g}}$ Dpto. Farmacología. Universitat de València (luisa.ferrandiz@uv.es) y hopto. Medicina Preventiva y Salud Pública, Ciencias de la Alimentación , Toxicología y Medicina Legal. Universitat de València (jesus.blesa@uv.es).

\section{\$EWWFW}

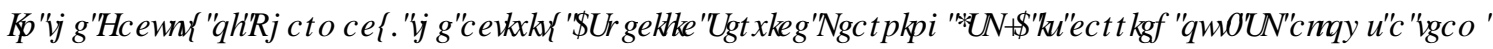

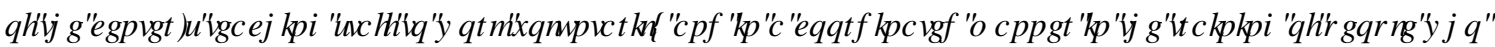

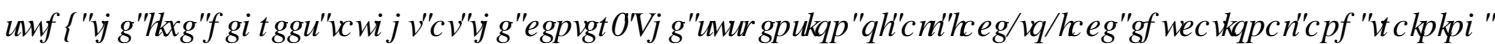

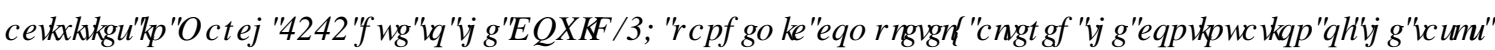

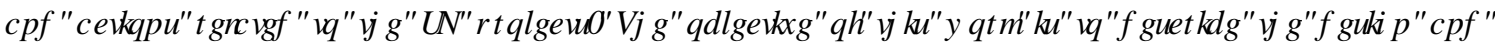

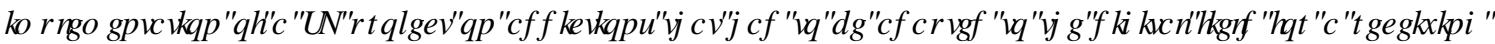

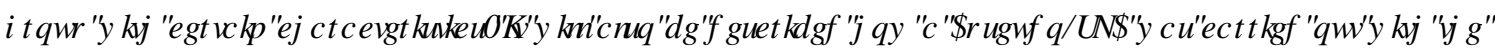

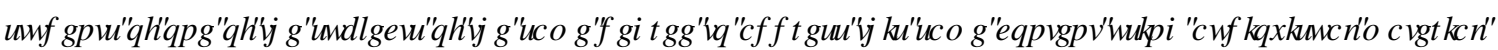

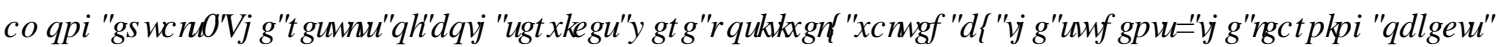

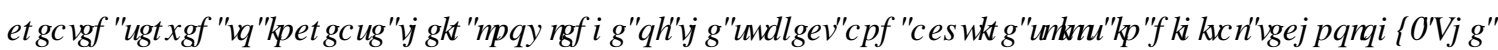

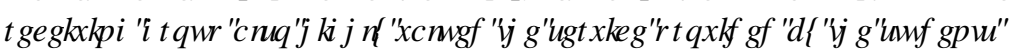

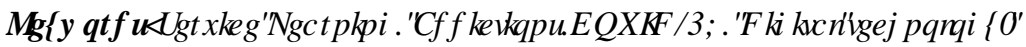

\section{HXP HQ}

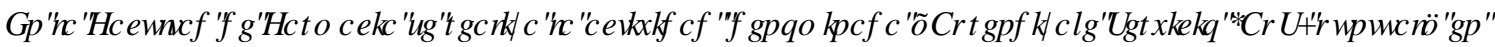

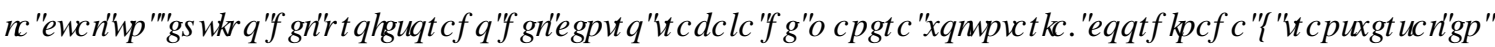

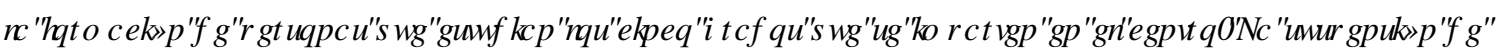

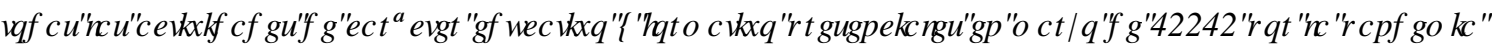

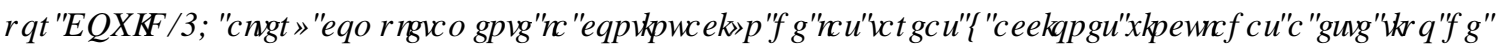

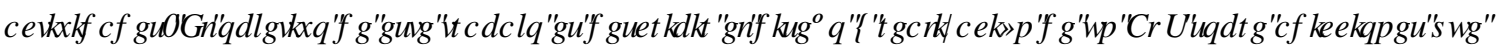

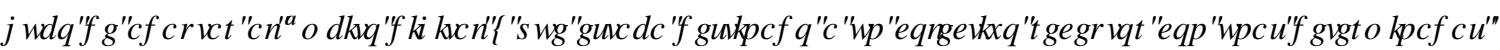

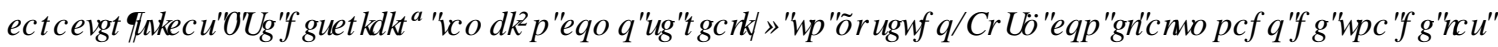

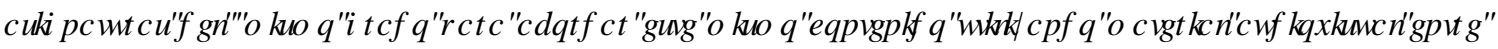

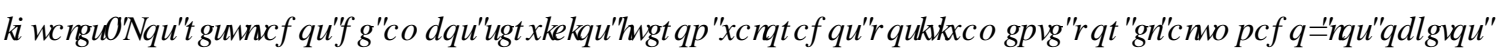

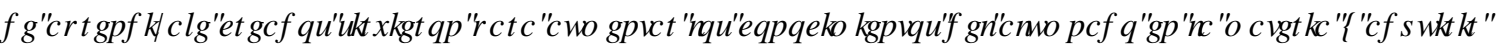

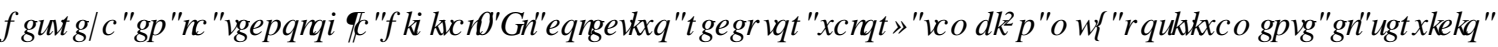
UHDQ] DORD प

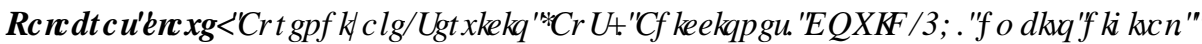




\section{Introducción}

El Aprendizaje-Servicio (ApS) es una metodología docente proactiva, cooperativa, participativa e inherentemente transformadora. Mediante este tipo de actividad educativa se fomenta el refuerzo de aspectos positivos para el estudiantado en tres ámbitos principales (Puig et al., 2006 ; Uruñuela, 2018):

- Currículum académico. Permite afianzar conocimientos teóricos obtenidos en la formación clásica y aplicarlos a la práctica. Mediante esta técnica, el estudiante puede afianzar los conocimientos adquiridos, así como hacerlos pertinentes para un contexto sociocultural determinado.

- Formación en valores. Permite la ubicación del futuro profesional en un contexto de sociedad, educando en valores como la responsabilidad social o la solidaridad.

- Vinculación de la comunidad. Ya que la intervención está enfocada en una necesidad explícita de la sociedad y fomenta la intervención de carácter profesional para tratar de hallar su solución.

En la Facultad de Farmacia de la Universitat de València, y enmarcado dentro del Programa Innocentre (Proyecto Innovación Educativa de Centro), se realiza la actividad denominada "ApS puntuales". Esta actividad se inició en el curso 2016-2017 y permite que un equipo del profesorado del centro trabaje de manera voluntaria y coordinada en la formación de personas que estudian los cinco grados que se imparten en el centro (Grado en Farmacia, Grado en Nutrición Humana y Dietética, Grado en Ciencia y Tecnología de los Alimentos, Grado en Ciencias Gastronómicas y Doble Grado en Farmacia y Nutrición Humana) en metodología ApS, realizando proyectos en determinados colectivos de la sociedad (asociaciones de vecinos, ONGs, centros educativos, colectivos en riesgo de exclusión social...) atendiendo a sus necesidades y orientado a ampliar las capacidades de estas personas. Al mismo tiempo que el alumnado (y el profesorado implicado) aprende, el colectivo receptor del servicio amplía sus conocimientos que le permitirán el acceso a recursos necesarios y que incentivarán la organización participativa y el uso democrático del poder como miembros activos de la sociedad.

La promoción y motivación para participar en la ejecución de los ApS puntuales en la Facultad de Farmacia se lleva a cabo a través de un vídeo (Figura 1) que se publicita por medio de correos electrónicos, redes sociales y de manera presencial en clase por profesorado participante en esta actividad. Esta publicidad se realiza en los meses de septiembre y octubre y acaba con la realización de una sesión presencial donde los coordinadores de la actividad informan sobre el programa (Figura 2), el cronograma de ejecución (Figura 3) y algunos estudiantes participantes en anteriores ediciones relatan su experiencia. El alumnado participante en la actividad recibe tres créditos de libre elección por la participación de manera conjunta en estas actividades. 


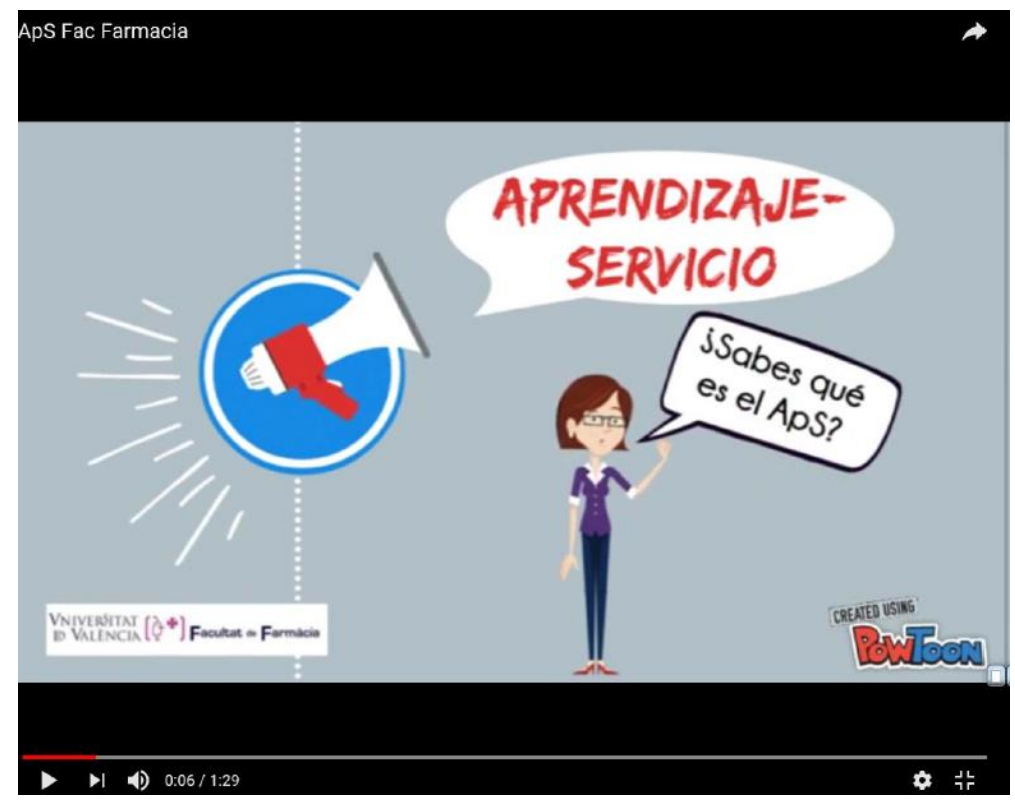

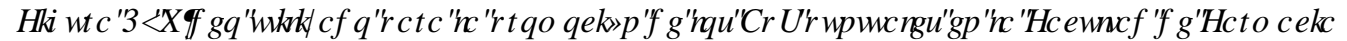

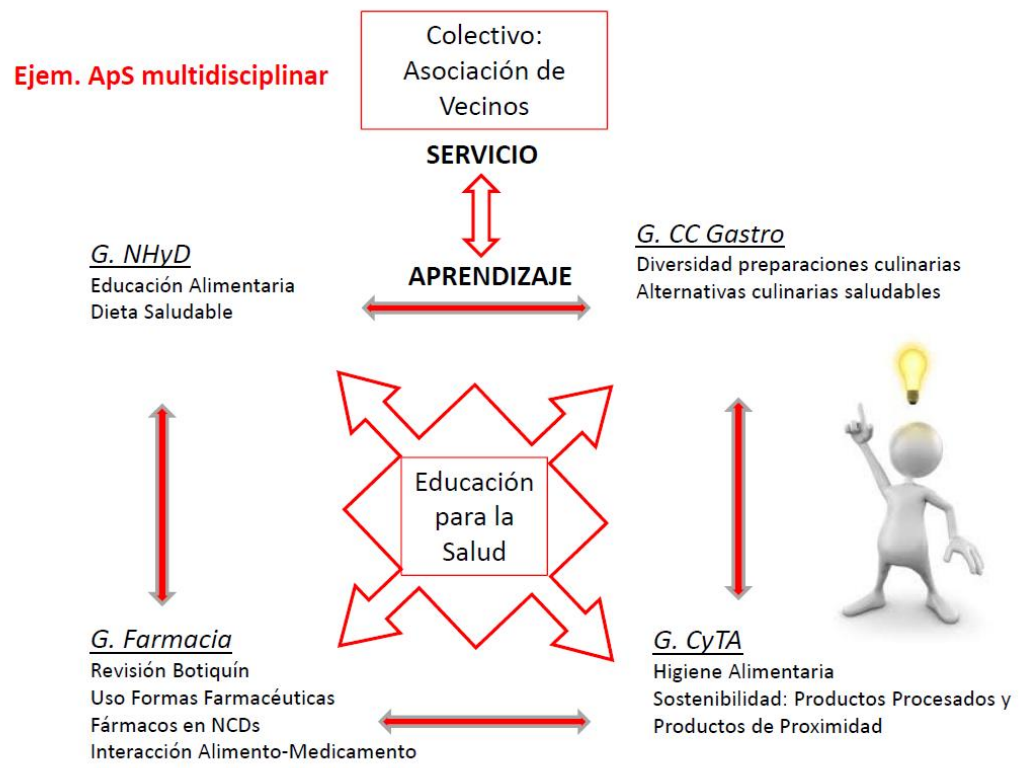

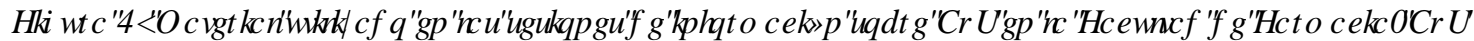

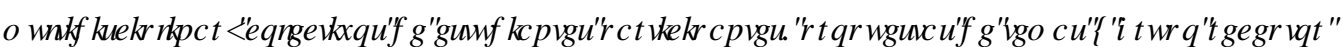




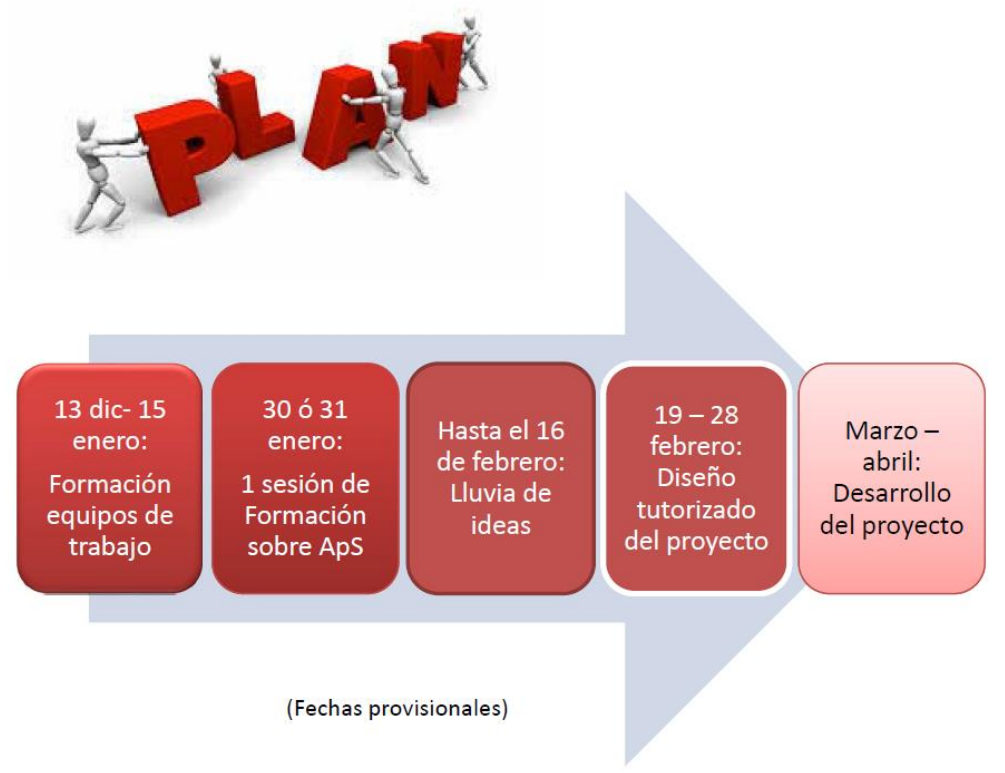

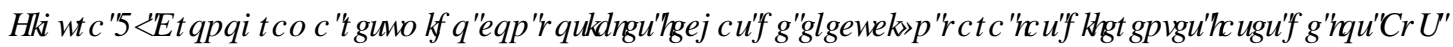

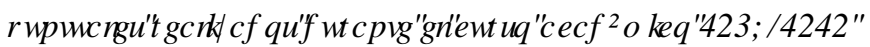

Como se puede observar en la Figura 2, la mayor parte de los servicios que los colectivos demandantes solicita es la impartición de talleres educativos-participativos de temas relacionados con la salud y estilos de vida saludables (dieta saludable, higiene alimentaria, uso de formas farmacéuticas...). Estos servicios se realizan de modo presencial mediante la ejecución de talleres y/o charlas repartidos en dos o tres sesiones de 90-120 minutos de duración en las sedes de las asociaciones, colegios, etc.

En el curso 2018-2019 se inscribieron 28 estudiantes pertenecientes a tres de los cinco grados del centro, de los cuales 15 estudiantes formaron cinco grupos de tres personas que fueron tutorizados por 15 docentes participantes. Diez estudiantes cursaron la formación en ApS y seis estudiantes finalizaron dos proyectos de ApS.

En el curso 2019-2020 se realizó la formación en ApS de 51 alumnos y alumnas de los cinco grados que se cursan en el centro. De estos, 34 participaron en diferentes proyectos ApS, un total de siete, de los cuales cuatro finalizaron satisfactoriamente, los otros otros se vieron truncados por la situación generada por la pandemia por COVID-19.

El objetivo de este trabajo es describir las estrategias alternativas que uno de los equipo de ApS multidisciplinar de la Facultad de Farmacia de la UV implementó para realizar el servicio que había solicitado el colectivo receptor. Estas estrategias, implementadas por la suspensión de todas las actividades de carácter educativo y formativo presenciales debido a la pandemia por COVID-19, potenciaron la capacidad de colaboración y la fluidez en el ámbito digital del alumnado así como su integración de manera real y eficaz en su práctica diaria y en su formación 


\section{Objetivos}

El objetivo de este trabajo es describir el diseño y realización de dos actividades educativas, basadas en ApS, y dirigidas a la sensibilización, información y prevención de diferentes tipos de adicciones. La primera actividad que se describirá es un taller educativo sobre estilos de vida y hábitos saludables en un Centro de Ayuda al Refugiado (CEAR) de la ciudad de València realizado por un grupo de alumnas de la Facultad de Farmacia y que tuvo que replanificarse y adaptarse al periodo de confinamiento por COVID19. La segunda actividad es un "pseudo-ApS" en el ámbito digital con el alumnado de una de las asignaturas del mismo grado para abordar la prevención de las adicciones en población general.

Para alcanzar dicho objetivo principal se proponen los siguientes objetivos específicos.

1. Descripción del servicio a realizar al colectivo demandante (CEAR) atendiendo a sus necesidades y características peculiares.

2. Descripción del material y actividades a realizar que inicialmente se propusieron para llevar a cabo el servicio en el colectivo demandante

3. Descripción de la replanificación y adaptación de los materiales y actividades que se tuvo que realizar debido al periodo de confinamiento por COVID-19 (marzo-junio 2020). Esta adaptación supuso la utilización de metodología digital al que ni el alumnado del centro ni el profesorado estaba acostumbrado para este tipo de actividades.

4. Descripción del "pseudo-ApS" que se propuso para el alumnado del grado de Farmacia con el objetivo de prevenir adicciones en población general.

5. Resultado de las actividades y evaluaciónes del taller en línea por el colectivo receptor y de los proyectos (ApS y “seudo-ApS”) por el alumnado.

\section{Desarrollo de la innovación}

\subsection{Descripción del servicio a realizar, características y necesidades del colectivo receptor}

El grupo de estudiantes que realizó el proyecto ApS estaba compuesto por cuatro personas de titulaciones diferentes (Grado en Farmacia, Grado en Nutrición Humana y Dietética y Grado en Ciencia y Tecnología de los alimentos). El colectivo receptor del servicio era un Centro de Ayuda al Refugiado (CEAR) situado en la ciudad de València y con el cual una de las alumnas del grupo ya tenía un contacto establecido previamente.

La directora del CEAR mantuvo desde el primer momento gran interés por el tema y, tras mantener varias reuniones presenciales con varias personas del grupo durante los meses de octubre y noviembre 2019, se propusieron una serie de talleres sobre temas de salud y estilos de vida (sobre todo alimentación y hábitos tóxicos). El grupo de alumnos comenzó el diseño del taller presencial dirigidos a un colectivo formado en su mayoría por hombres entre 20-40 años, de diferentes países de procedencia (África subsahariana y Latinoamerica principalmente) y con un nivel socio-económico y cultural bajo.

\subsection{Descripción del material y actividades a realizar que inicialmente se propusieron.}

El taller se distribuiría en tres sesiones de una hora de duración cada una de ellas a realizar en los meses de abril y mayo de 2020. Las sesiones comenzarían con una breve exposición de conceptos teóricos para lo cual se utilizaría presentaciones SRZHUSRLQWunto con una serie de actividades dinamizadoras (juegos verdadero-falso acerca de mitos, falsas creencias, etc.) (Figura 4). Continuaría con una actividad participativa y acabaría con un juego por equipos. La actividad se evaluaría a través de una encuesta que se distribuiría en los últimos 15 minuos de la última sesión (tercer día). 

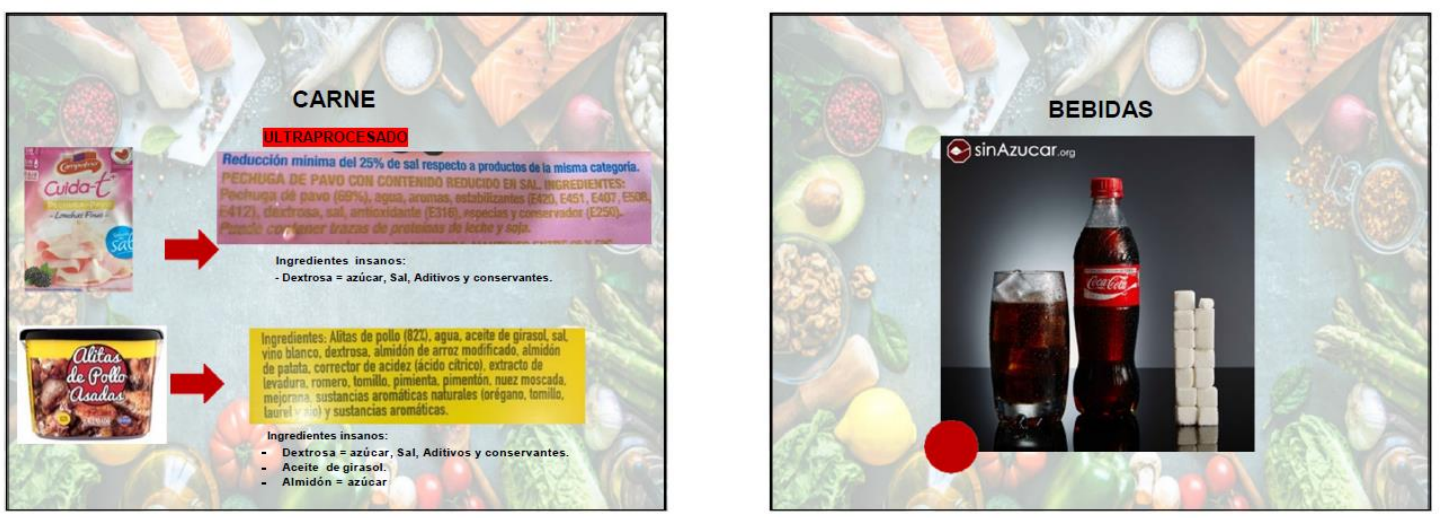

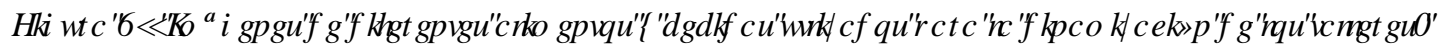

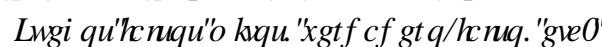

\subsection{Descripción de la replanificación y adaptación de los materiales y actividades que se realizó durante el periodo de confinamiento}

Con fecha del 13 de marzo de 2020, se publicó en la Universitat de València la Resolución del Rectorado de medidas excepcionales de carácter general en aplicación de las resoluciones del Gobierno de la Generalitat Valenciana para limitar la propagación del contagio del coronavirus. Esta resolución implicó la interrupción del servicio universitario y, como primer punto, la suspensión de todas las actividades de carácter educativo y formativo presenciales. Esta resolución también alteró completamente la continuación de las tareas y acciones vinculadas a los proyectos ApS. La imposibilidad de realizar los talleres presenciales de las actividades ApS, unida a la incertidumbre existente sobre el desarrollo y evaluación de otras actividades académicas, hizo que varios grupos que habían manifestado su interés por participar en el proyecto lo abandonaran.

El grupo de estudiantes implicados en nuestro caso pasó de cuatro componentes a únicamente dos alumnas que cursaban el Grado en Farmacia. Ante la imposibilidad de realizar las sesiones planificadas de manera presencial, se optó por la preparación de material audiovisual para su uso de manera virtual. Además, y dado que se tenía previsto empezar a realizar los talleres en abril y la situación de incertidumbre no permitió planificar estrategias definitivas hasta mayo, la temática del taller se redujo a salud y bábitos tóxicos.

El nuevo objetivo del servicio se discutió y consensuó de nuevo con la directora del CEAR. Tras varios contactos se decidió tratar el tema de hábitos tóxicos abordando fundamentalmente el alcoholismo y la ludopatía (adicción a los juegos de azar). El objetivo del servicio que las alumnas realizarían en el colectivo receptor fue:

- Explicar los conceptos de "Alcoholismo", "Ludopatía”, “Adicción”, "Síndrome de Abstinencia" y qué factores o condiciones pueden predisponernos a ello.

- Explicar una serie pruebas sencillas pueden utilizarse de manera individual para realizar un autodiagnóstico de dependencia y/o adicción y/o consumo de riesgo.

- Informar de los servicios a los que se puede acudir en caso de necesitar ayuda, consejo o cualquier tipo de información sobre alcoholismo y ludopatía. 
Para alcanzar estos objetivos las alumnas diseñaron el siguiente material audiovisual:

- Un vídeo (mp4) de aproximadamente 10 minutos de duración en el que se tratatará de manera resumida todos estos aspectos (Figura 5).

- Dos dípticos donde se resumiese en qué consiste y como se pueden detectar el alcoholismo y la ludopatía (Figura 6).
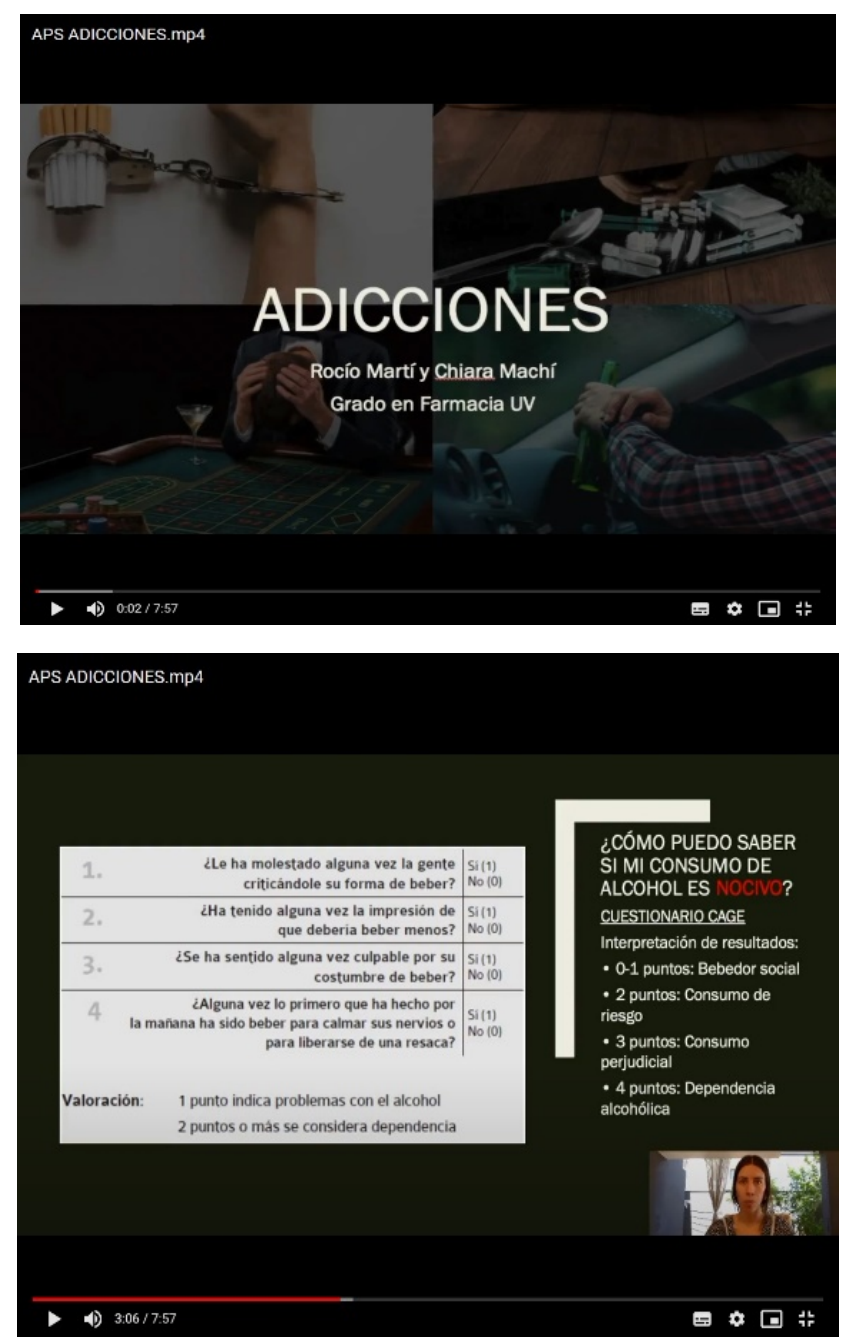

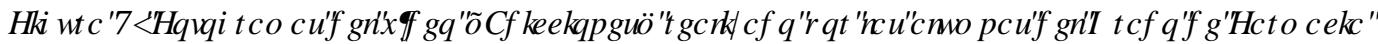



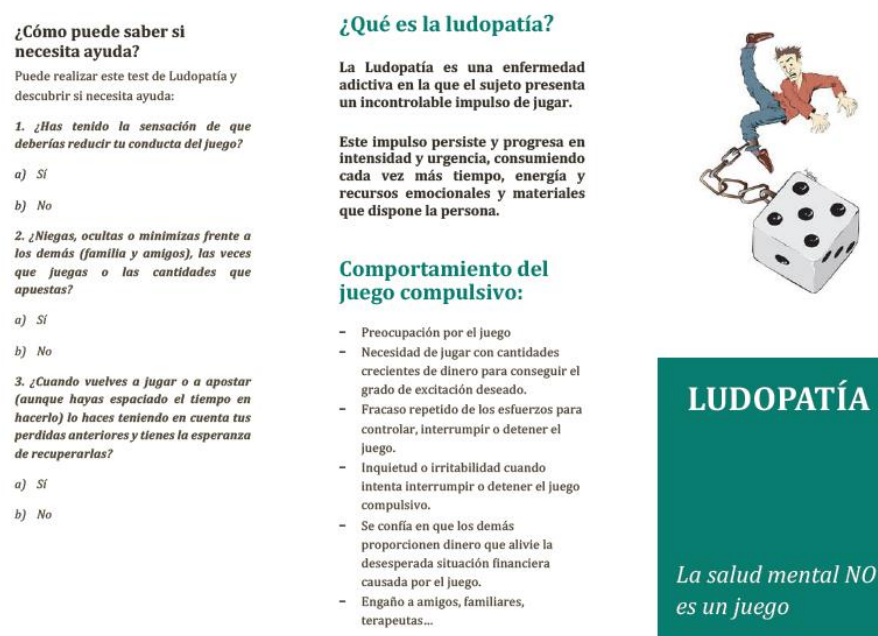

La salud mental NO

es un juego

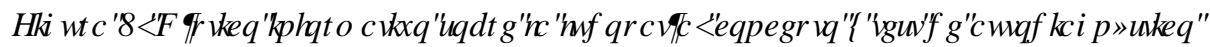

\subsection{Descripción del "pseudo-Aps" propuesto para el alumnado del Grado de Farmacia}

Una de las asignaturas troncales en los planes de estudios del Grado en Farmacia en la Universitat de València es "Salud Pública". En esta asignatura anual de nueve ECTS hay contenido teórico explícito sobre el consumo de sustancias tóxicas (alcohol, tabaco y otras drogas de abuso). En los últimos días del mes de marzo, y coincidiendo con la clase teórica sobre este tema impartida de manera no presencial, se propuso al alumnado de dos de los tres grupos de esta asignatura (inglés y castellano), y en la cual una de las profesoras tutoras de ApS impartía docencia, una actividad, que se denominó "pseudo-ApS".

La actividad consistía en la elaboración de un vídeo sobre hábitos saludables relacionados con la prevención de las conductas adictivas. En este vídeo se debían transmitir mensajes saludables y educativos sobre prevención del consumo de alcohol, otras drogas u otras conductas adictivas (pantallas, juego patológico, etc.). La actividad propuesta serviría al alumnado para desarrollar competencias y aprender contenidos pero además, actuaría como prevención de conductas adictivas en jóvenes. El vídeo tendría una duración máxima de dos minutos y debía estar relacionado con la prevención de conductas adictivas; promoviendo procesos de reflexión crítica sobre los riesgos derivados del consumo de drogas u otras conductas adictivas, y en especial, hacer referencia a alguno de los siguientes temas:

a. Alternativas al consumo de alcohol u otras drogas.

b. Maneras de hacer frente al consumo.

c. Estrategias de autocontrol y de minimización de los riesgos.

d. Reflexión sobre juegos y apuestas en línea.

e. Uso adecuado de las "pantallas".

f. Mitos y creencias sobre drogas y otras conductas adictivas.

g. Implicaciones sociales y económicas del consumo de sustancias u otras adicciones.

h. Las drogas y otras adicciones desde la perspectiva de género.

Además, el alumnado podía presentarse al concurso "Adicciones: tu punto de mira" (Novena Edición) organizado por el Tu Punto, un programa de la asociación PDS (Promoció i Desenvolupament Social), 
financiado por la Delegación del Gobierno para el plan nacional sobre drogas (Ministerio de Sanidad), y que cuenta con la colaboración de la Generalitat de Catalunya, la Junta de Castilla y León, la Asociación Española de Estudio en Drogodependencias (AESED) y la Asociación Alborada.

Tanto si se participaba en la elaboración del vídeo como si no se debía contestar a estas dos preguntas:

1. ¿Me ayuda la elaboración de este tipo de vídeos en el aprendizaje como estudiante universitario?

2. ¿Puedo ayudar yo a un igual a modificar su actitud o conocimiento sobre un determinado problema de salud a través de un vídeo y su difusión por redes sociales?

\section{Resultados}

A continuación se expondrán los resultados obtenidos divididos en dos apartados según el ámbito donde se realizaron.

\subsection{Resultados del ApS realizado para el CEAR de la ciudad de València}

Como resultado del ApS realizado por las dos alumnas del Grado de Farmacia de la UV para el CEAR de la ciudad de Valéncia se han generado diferentes materiales audiovisuales que podrán ser utilizados para talleres posteriores. Estos materiales son: un vídeo de 10 minutos de duración y dos dípticos (formato pdf) con información sobre la detección de alcoholismo y ludopatía y su tratamiento. El grado de satisfacción por parte de las personas responsables del CEAR con el material generado fue de muy satisfactorio (5 en una escala de $0-5 ; 3$ personas). Del colectivo al que iba dirigido el servicio formado por las personas que acudían al CEAR no se pudo recoger información cuantitativa sobre el grado de satisfacción con los materiales utilizados. No obstante señalamos que los comentarios generales de este colectivo recibidos por parte de los responsables del CEAR que posteriormente nos han transmitido han sido muy positivos. El vídeo fue visualizado por el grupo de personas que acude al CEAR a recibir los servicios que este centro ofrece; todas ellas mostraron gran interés y guardaron los dípticos con la información.

Las dos alumnas que realizaron el ApS mostraron gran satisfacción con el trabajo debido principalmente a varios factores:

- Aprendizaje en conceptos sobre adicciones que desconocían.

-Aprendizaje de técnicas audiovisuales (grabación de vídeos, elaboración presentaciones para un público determinado, síntesis de conceptos adecuadamente...).

- Colaboración y cooperación con la sociedad civil.

- Generación de utilidad del trabajo realizado para el colectivo receptor.

\subsection{Resultados del pseudo-ApS realizado en los dos grupos de alumnos de la asignatura Salud Pública del Grado en Farmacia de la Universitat de València}

De los 94 alumnos matriculados en la asignatura de Salud Pública del Grado en Farmacia en los grupos de castellano y/o inglés solo una de ellas realizó el vídeo propuesto (Figura 7). 


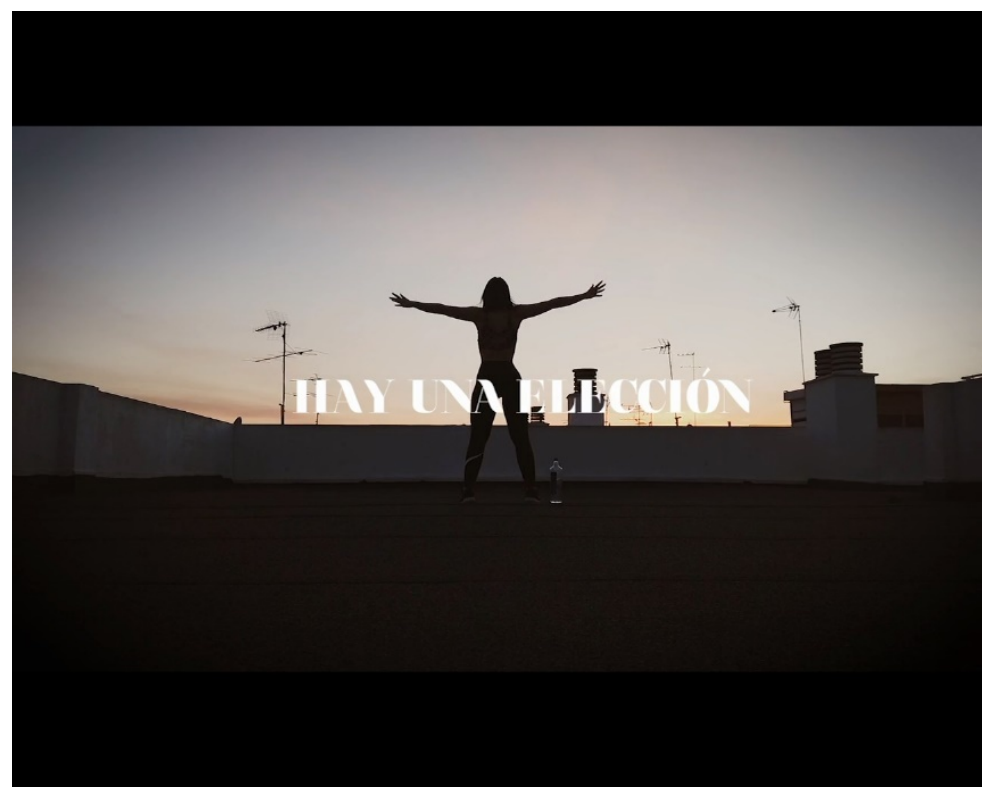

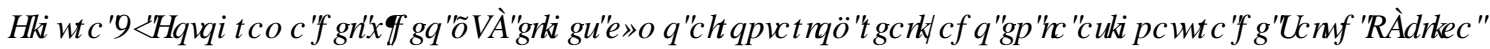

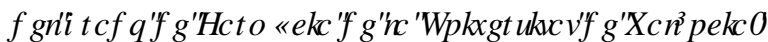

La alumna destacó que "para la realización el vídeo pensé cómo podía reflejar la dualidad a la que se enfrenta la protagonista, entre escoger un estilo de vida saludable, donde se trata de manifestar que, con hábitos como el ejercicio, la persona consigue distintos beneficios tanto a nivel físico como mental, o escoger un estilo de vida donde el consumo de alcohol y otras drogas se produce día a día, reflejándose a lo largo del vídeo el declive que sufre la protagonista; desde el comienzo donde esos hábitos malsanos pueden producir algún tipo de satisfacción, hasta el final donde la decrepitud producida por las propias acciones de uno mismo generan tal nivel de declive que se llega a perder la propia esencia de la persona".

El 63,5\% del alumnado contestó a las preguntas sobre la elaboración del vídeo; la mayoría de las personas contestaron que este tipo de actividades resulta muy positivo para su aprendizaje y que lo consideran muy motivador y "divertido" pero que puedo suponer una alta carga de trabajo. Respecto al beneficio que puede suponer para un igual hay dos tipos de respuestas; aquellas en las que se refleja una clara duda en su utilidad cuando la persona ya sufre una adicción y otras en las que claramente se opina que en prevención primaria este tipo de vídeos podría ser muy útil junto a otras medidas preventivas.

El vídeo fue presentado al concurso "Adicciones: tu punto de mira" (Novena Edición) organizado por el Tu Punto por la alumna que lo realizó. Desafortunadamente no obtuvo ningún premio pero se consiguió que parte del alumnado del Grado de Farmacia visitará la página del concurso y visualizará los vídeos

\section{Conclusiones}

En primer lugar, la motivación de las dos alumnas que realizaron el ApS ha sido muy alta. La aceptación de la actividad, a pesar de suponer una carga de trabajo fue del $100 \%$. Se debe mencionar la buena disposición del alumnado que finalmente participó para adaptarse a los cambios; sin embargo se necesitaría analizar con más profundidsad las causas por las que gran parte de los participantes en ApS decidieron abandonar ante el confinamiento y/o incertidumbre. Los objetivos de aprendizaje creados (material audiovisual) sirvieron como herramienta para incrementar la atención del alumnado sobre el tema y a elaborar comentarios constructivos sobre el conocimiento derivado. Las alumnas agradecen desarrollar su 
competencia digital y tener protagonismo en la creación de objetos de aprendizaje;lo que concuerda con los resultados obtenidos en otras disciplinas y centros (Almaiah et al., 2020). La motivación de las tareas digitales mediante ApS puede ir más allá de entender simplemente cómo usar la tecnología, e implica integrarla de manera real y eficaz en su práctica diaria y en su formación. (Marquès, 2000; Watermeyer et al.,2020).

En cuanto a la actividad que se propuso para los grupos de Salud Pública (“pseudo-ApS”) la experiencia ha sido muy positiva en términos de comprensión de fortalezas y debilidades del desarrollo de la actividad docente en línea. La baja participación para la elaboración del vídeo podría mejorarse empleando las estrategias de motivación adecuadas. Sin embargo, para llevar a cabo esta mejora es necesario optimizar el tiempo dedicado a cada persona y a cada actividad que se realiza. También deberíamos contemplar más profundamente cómo evaluarla, dado que el alumnado opina que son actividades que consumen mucho tiempo pero que pueden resultar muy interesantes y motivadoras (Zuo et al., 2020)

Si bien es cierto que las actividades que se proponen deben motivar y conseguir que participe la totalidad del grupo, la propuesta de "pseudo-ApS" nos ha obligado a replantearnos si quizás se deberían reducir contenidos para aumentar la calidad de los mismos adaptando nuestra docencia a los cambios que se producen en esta época de incertidumbre. Además, es bien sabido que el alumnado está acostumbrado a que cualquier acción que realice debe estar recompensada con una nota en la evaluación.

No obstante, cabe destacar que los resultados son de un solo año y no de la totalidad del alumnado de la titulación y por lo tanto no son suficientes para establecer las conclusiones de forma global. Se propone para trabajos futuros analizar la evolución en años posteriores y la comparación con otros aspectos que no se trabajan con ApS.

\section{Bibliografía}

ALMAIAH, M. A., AL-KHASAWNEH, A., Y ALTHUNIBAT, A. (2020). "Exploring the critical challenges and factors influencing the E-learning system usage during COVID-19 pandemic" en Education and Information Technologies, 25, 5261-5280 < https://doi.org/10.1007/s10639-020-10219-y>.

"ApS Fac Farmacia" $<R X W E H<$ https://youtu.be/fisXzLTiJ40> [Consulta: 20 de marzo de 2021] .

LUJÁN-GARCÍA, C.I. (1999). La motivación: Un factor relevante en el proceso de enseñanza/aprendizaje de lenguas extranjeras. Boletín Millares Carlo, 18, 269-278.

MARQUĖS, P. (2000). Ventajas e inconvenientes del material multimedia educativo. Departamento de Pedagogía Aplicada, Facultad de Educación, UAB $<$ http://peremarques.net/ventajas.htm $>$ [Consulta: 22 de marzo de 2020].

PUIG, J.M; BATLLE, R.; BOSCH, C. y PALOS, J. Aprendizaje-servicio. Educar para a la ciudadanía. Barcelona, Editorial Octaedro, 2006.

SALINAS, J. (1996). "Multimedia en los procesos de enseñanza - aprendizaje: Elementos de discusión”. Ponencia en el Encuentro de Computación Educativa. Santiago de Chile, 2-4 mayo.

"Tu eliges cómo afrontarlo" 9IPHRK https://vimeo.com/425809370> [Consulta: 20 de marzo de 2021] .

URUÑUELA, P. M. (2018). La Metodología del Aprendizaje-Servicio. Madrid: Narcea.

WATERMEYER, R., CRICK, T., KNIGHT, C. Y GOODALL, J. (2020). "COVID-19 and digital disruption in UK universities: afflictions and affordances of emergency online migration" en Higher Education, 81, 623-641 <https://doi.org/10.1007/s10734-020-00561-y>.

ZUO, L., DILLMAN, D., \& MILLER JUVE, A. (2020). "Learning At-Home During COVID-19: A Multiinstitutional Virtual Learning Collaboration" en Medical Education, 54, 7, 664-665

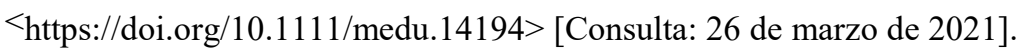

